\title{
APLIKASI UMPAN RAYAP BERBAHAN AKTIF HEXAFLUMURON PADA DOSIS BERBEDA DALAM PENGENDALIAN SERANGAN RAYAP DI PERKEBUNAN KELAPA SAWIT
}

(Application of termite bait with active ingredients Hexaflumuron at different dosage on termite control in oil palm plantation)

\author{
Farah Diba $^{1}$, Marselinus T M Simatupang ${ }^{1}$, Lukas Siahaan ${ }^{1}$, Nurhaida ${ }^{1}$, \\ M. Idham ${ }^{1}$, M. Yuli Irianto ${ }^{2}$, Zulfadli ${ }^{2}$ \\ ${ }^{1}$ Fakultas Kehutanan Universitas Tanjungpura, Jalan Imam Bonjol Pontianak, 78124 \\ ${ }^{2}$ PT. Dow Agro Sciences Indonesia, Jakarta \\ Email : farahdiba@fahutan.untan.ac.id
}

\begin{abstract}
Subterranean termites Coptotermes curvignathus has found as pest in oil palm plantation. The research aimed to control the termites in oil palm plantation using Hexaflumuron bait with different dosage. Location of research was oil palm plantation at Purun village in Mempawah Regency. The study was conducted by a completely randomized design method. The research treatment was dose of Hexaflumuron termite bait, consisting of 30 gram and 60 gram. Three blocks was choosing as a sample treatment consists of block $H$ 35, block $H 38$ and block $H$ 39. Hexaflumuron bait has weight 30 gram. Treatment dose of 30 gram was conducted with lay down the bait of Hexaflumuron at the mud tunnel of termites in the trunk of oil palm. Treatment dose of 60 gram was conducted with lay down two bait of Hexaflumuron at the mud tunnel of termites in the trunk of oil palm in the different place. Then inspection of bait consumption was conducted every week. Data of bait consumption and termites elimination was collected. Results of the research showed that Hexaflumuron bait was consumed by termites up to $100 \%$. The bait has attracted the termites to consume and non-repellent to termites. After four until seven week consumption the Hexaflumuron bait, termites eliminated from the oil palm. The result of variance analysis showed that there was no significance difference between the dose of 30 gram and 60 gram on the termite consumption level. Hexaflumuron bait was effective for termites elimination in oil palm plantation within four until seven weeks and dose 30 gram was optimum for termites elimination.
\end{abstract}

Keywords: Coptotermes curvignathus, hexaflumuron, oil palm, termites bait, termites control

\section{PENDAHULUAN}

Rayap merupakan serangga yang mendekomposisi selulosa yang terdapat pada kayu. Peranan rayap sangat penting di alam karena rayap membuat tanah menjadi lebih subur sebagai hasil dari proses dekomposisi serasah yang dilakukan oleh rayap. Namun rayap juga dikenal sebagai hama bagi tanaman perkebunan kelapa sawit. Beberapa peneliti menyatakan rayap menjadi hama yang merugikan di perkebunan kelapa sawit, dan jenis yang ditemukan meliputi Coptotermes curvignathus Holmgren, Schedorhinotermes javanicus, Macrotermes gilvus dan Microtermes sp 
(Diba 2015, Habibi dkk 2017 dan Nandika 2014).

Tanaman kelapa sawit (Elaeis guineensis Jacq.) mulai ditanam di Indonesia pada tahun 1848 di Kebun Raya Bogor. Selanjutnya tanaman kelapa sawit tersebar di wilayah Sumatera, yang meliputi di Muara Enim (1869), Musi Hulu (1870), Belitung (1890), Sungai Liput (Aceh) dan Pulau Raja (Asahan) pada tahun 1911 (Risza, 1994). Saat ini di Provinsi Kalimantan Barat luas perkebunan kelapa sawit mencapai 1.060.251 ha (Dinas Perkebunan Provinsi Kalimantan Barat, 2016). Serangan rayap tanah pada perkebunan kelapa sawit tidak hanya terjadi di Provinsi Kalimantan Barat. Nandika (2014) menyatakan serangan rayap di perkebunan kelapa sawit terjadi di Pulau Sumatera, Pulau Kalimantan dan Pulau Sulawesi. Rayap yang paling banyak menyerang adalah rayap tanah Coptotermes curvignathus Holmgren.

Pengendalian serangan rayap di kebun kelapa sawit masih mengandalkan sistem penyemprotan bahan kimia termitisida cair ke tanaman kelapa sawit. Namun hal ini ternyata tidak efektif karena serangan rayap masih berulang. Teknologi terbaru dalam pengendalian rayap adalah dengan menggunakan metode umpan (baiting system). Umumnya bahan aktif yang digunakan dalam sistem umpan adalah bahan penghambat sintesis khitin, seperti chlorfluazuron (Peters et al. 2008) dan Hexaflumuron (Nandika dkk 2015). Teknologi pengendalian serangan rayap dengan sistem umpan dengan bahan aktif Hexaflumuron yang digunakan untuk pengendalian rayap di pemukiman mulai dikembangkan untuk pengendalian rayap di perkebunan (Diba dkk 2016; Toni dkk 2015; Tampubolon dkk 2016). Penelitian yang dilakukan masih menggunakan umpan rayap Hexaflumuron dalam bentuk prototype dan belum untuk skala komersil. Hasil penelitian menunjukkan umpan rayap dapat mengeliminasi koloni rayap dalam waktu 40-60 hari. Jumlah konsumsi umpan bervariasi, sebesar 30-65 gram per koloni rayap dalam satu tanaman kelapa sawit. Oleh karena itu dalam penelitian ini bertujuan untuk mengeliminasi koloni rayap C. curvignathus Holmgren dengan umpan rayap Hexaflumuron yang telah dikemas dalam bentuk siap pakai, dan menganalisa jumlah konsumsi umpan rayap yang optimal dalam pengendalian rayap di kebun kelapa sawit.

\section{METODE PENELITIAN}

Penelitian dilakukan di kebun kelapa sawit yang terletak di Kecamatan Anjungan, Kabupaten Mempawah yaitu kebun purun selatan milik PT. Peniti Sungai Purun. Lokasi sampel penelitian dipilih pada blok yang terserang hebat oleh rayap yaitu Blok H35, H38, H39. Waktu penelitian dilaksanakan pada bulan Februari - Juni 2017. Bahan yang digunakan adalah pohon kelapa sawit yang dijadikan sampel penelitian, umpan rayap dengan bahan aktif Hexaflumuron yang diperoleh dari PT.Dow Agro Sciences Indonesia, kayu karet, dan cat warna merah. Alat yang digunakan meliputi staples tembak, cutter, kantong plastik hitam, timbangan analitik, kertas label, oven dan desikator.

Tanaman kelapa sawit yang dipilih sebagai sampel adalah tanaman dengan tingkat serangan rayap sangat berat dan 
berat dan umur tanaman 4 tahun. Klasifikasi serangan rayap sangat berat meliputi serangan rayap dari permukaan batang, diantara pelepah sampai ke pucuk, dan terdapat liang kembara rayap di pelepah dan batang kelapa sawit yang di dalamnya terdapat sekumpulan rayap aktif. Klasifikasi serangan rayap berat meliputi terdapat serangan rayap dari bagian bawah batang kelapa sawit sampai bagian pelepah dan tidak sampai ke daerah pucuk, liang kembara rayap terdapat di bagian batang dan beberapa pelepah.

Tahapan penelitian pengumpanan meliputi pada tiga blok sampel penelitian, yaitu pada blok H35, H38, dan H39. Setiap blok dipilih 3 tanaman kelapa sawit untuk dosis 30 gram dan 3 tanaman kelapa sawit untuk dosis 60 gram sehingga total sampel adalah 18 tanaman kelapa sawit. Pada perlakuan dosis 30 gram, satu umpan rayap dengan bahan aktif Hexaflumuron seberat 30 gram diletakkan pada satu tanaman kelapa sawit. Peletakan dilakukan pada bagian pelepah tanaman. Selanjutnya umpan ditutup dengan plastik hitam agar terlindung dari gangguan organisme lain dan cahaya matahari serta rayap dapat lebih cepat untuk mengkonsumsi. Pada perlakuan dosis 60 gram, dua umpan rayap dengan bahan aktif Hexaflumuron masingmasing seberat 30 gram diletakkan pada satu tanaman kelapa sawit. Peletakan dilakukan pada bagian pelepah tanaman kelapa sawit pada lokasi yang berbeda, yaitu pada bagian yang di liang kembara banyak terdapat rayap. Selanjutnya umpan ditutup dengan plastik hitam agar terlindung dari gangguan organisme lain dan cahaya matahari serta rayap dapat lebih cepat untuk
mengkonsumsi.Pengamatan dilakukan setiap pekan sampai koloni rayap tereliminasi yang ditandai dengan tidak adanya rayap di liang kembara yang terdapat pada tanaman kelapa sawit. Data yang dikumpulkan adalah jumlah konsumsi umpan rayap Hexaflumuron dan lama waktu eliminasi rayap setelah mengkonsumsi umpan rayap Hexaflumuron.

Setelah rayap tereliminasi, dilakukan pemantauan serangan balik rayap. Hal ini bertujuan untuk mengetahui waktu serangan balik rayap setelah eliminasi. Patok pemantau serangan rayap terbuat dari kayu karet dengan ukuran $2 \mathrm{~cm}$ x 2 $\mathrm{cm}$ x $30 \mathrm{~cm}$. Bagian atas patok diwarnai dengan cat warna merah sebagai tanda serta untuk mempermudah pemantauan di lapangan. Patok pemantau ditanam atau ditancapkan secara vertikal ke dalam tanah sedemikian rupa dengan $2 / 3$ bagian terbenam di dalam tanah. Setiap pohon sampel dipasang patok pemantau sebanyak empat buah yang terdiri atas tiga buah ditanam di tanah dengan radius 1,5 meter dari tanaman kelapa sawit dan satu buah dipasang pada bagian pelepah bekas peletakan umpan. Pengamatan dilakukan setiap pekan dengan lama pemantauan selama \pm 2 bulan.

\section{HASIL DAN PEMBAHASAN}

Pekan pertama pengamatan umpan rayap Hexaflumuron menunjukkan ratarata di setiap blok umpan mulai dikonsumsi oleh rayap. Rayap membawa tanah masuk ke dalam umpan. Rayap membuat liang kembara di dalam umpan. Pengamatan pada pekan kedua dan ketiga menunjukkan umpan rayap dikonsumsi rayap dan hampir seluruh bagian umpan 
ditutupi dengan tanah. Hal ini menunjukkan umpan rayap dengan bahan aktif Hexaflumuron disukai oleh rayap dan memiliki palatabilitas yang tinggi. Tanaman kelapa sawit banyak diserang oleh rayap tanah Coptotermes curvignathus Holmgren karena memiliki kandungan selulosa yang tinggi. Penelitian Hermawan dkk (2014) menyatakan kelapa sawit mengandung holoselulosa sebesar 82,534\%-88,328\% dan kandungan alpha selulosa sebesar 11,243\%-68,761\%.

Pengamatan pekan ke empat sebanyak delapan umpan rayap pada tanaman kelapa sawit habis dikonsumsi rayap. Selanjutnya pengamatan pada pekan ke lima sudah terdapat rayap yang mengalami eliminasi pada beberapa sampel tanaman kelapa sawit. Tanda-tanda rayap mengalami eliminasi yaitu tanah liang kembara rayap mengering, pada umpan dan di dalam liang kembara tidak ada rayap serta ditemukan bangkai rayap yang mati di pelepah kelapa sawit. Rayap mengalami kematian dan tereliminasi ratarata pada pekan ke lima dan ke tujuh setelah mengkonsumsi umpan Hexaflumuron. Kondisi umpan pada saat pertama kali instalasi, pekan pertama dan pekan ke empat disajikan pada Gambar 1.
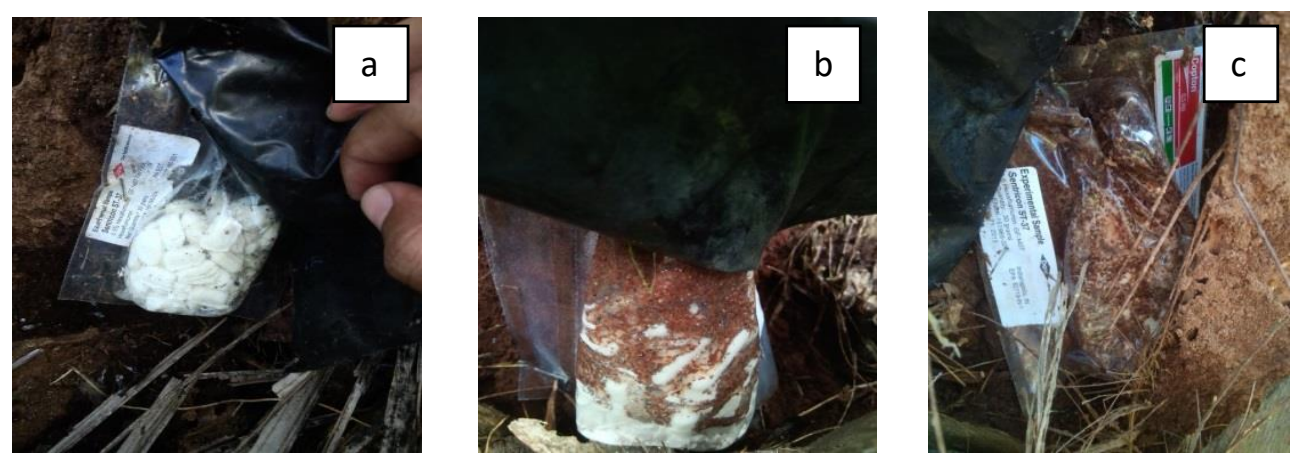

Gambar 1. Kondisi umpan rayap Hexaflumuron pada (a) pertama kali instalasi (b) satu pekan setelah instalasi dan mulai dikonsumsi oleh rayap Coptotermes curvignathus Holmgren (c) empat pekan setelah instalasi dan dipenuhi tanah oleh rayap Coptotermes curvignathus Holmgren (Condition of Hexaflumuron bait on (a) first time installation (b) one week after installation and start to consumption by subterranean termites Coptotermes curvignathus Holmgren (c) four week after installation and the bait was full with soil by subterranean termites Coptotermes curvignathus Holmgren)

Konsumsi umpan Hexaflumuron oleh rayap Coptotermes curvignathus Holmgren dari 3 blok penelitian setelah lima pekan dan tujuh pekan pengamatan rata-rata mencapai $90 \%-100 \%$ pada dosis 30 gram dan sebesar $66 \%-100 \%$ pada dosis 60 gram. Nilai rata-rata konsumsi umpan pada dosis 30 gram mencapai $100 \%$ pada Blok H35 dan
H38, dan sebear 90\% pada Blok H39. Sementara itu nilai rata-rata konsumsi umpan pada dosis 60 gram mencapai $100 \%$ pada Blok H35, 93\% pada Blok H39 dan $66 \%$ pada Blok H38. Nilai rata-rata konsumsi umpan pada blok $\mathrm{H}$ 35 lebih tinggi baik dari dosis 30 gram dan dosis 60 gram dari pada blok yang lainnya. 
Tingginya nilai konsumsi umpan Hexaflumuron oleh rayap Coptotermes curvignathus Holmgren menunjukkan bahan aktif Hexaflumuron disukai oleh rayap. Rayap aktif menyebarkan racun dengan proses trofalaksis ke semua anggota koloni dan tidak ada efek penolakan (repellen) rayap terhadap umpan Hexaflumuron. Beberapa peneliti mengeksplorasi bahan alam sebagai bahan aktif umpan. Penelitian Sari dkk (2014) menggunakan ekstrak daun Sirsak (Annona muricata L.) sebagai bahan umpan untuk pengendalian rayap Coptotermes curvignathus Holmgren. Nabu dkk (2015) menggunakan minyak atsiri dari kulit jeruk Citrus nobilis, Pratiwa dkk (2015) menggunakan ekstrak buah Mengkudu dan Salam dkk (2014) menggunakan ekstrak daun gulma Sembung Rambat (Mikania micrantha
Kunth). Hasil penelitian tersebut menunjukkan bahan alam dapat digunakan sebagai umpan rayap, tetapi belum diuji secara lapang. Hexaflumuron merupakan bahan aktif yang menghambat pembentukan khitin rayap dan telah diuji dalam skala laboratorium. Pengujian skala lapang telah dilakukan untuk mengendalikan rayap di perumahan dan berhasil dengan baik. Toni dkk (2015), Diba dkk (2016) dan Tampubolon dkk (2016) melakukan penelitian dengan umpan rayap Hexaflumuron untuk pengendalian rayap di kebun kelapa sawit. Umpan Hexaflumuron yang digunakan masih dalam bentuk formulasi laboratorium. Penelitian ini menggunakan umpan Hexaflumuron dalam bentuk ready for commercial use. Konsumsi umpan rayap Hexaflumuron disajikan pada Gambar 2.

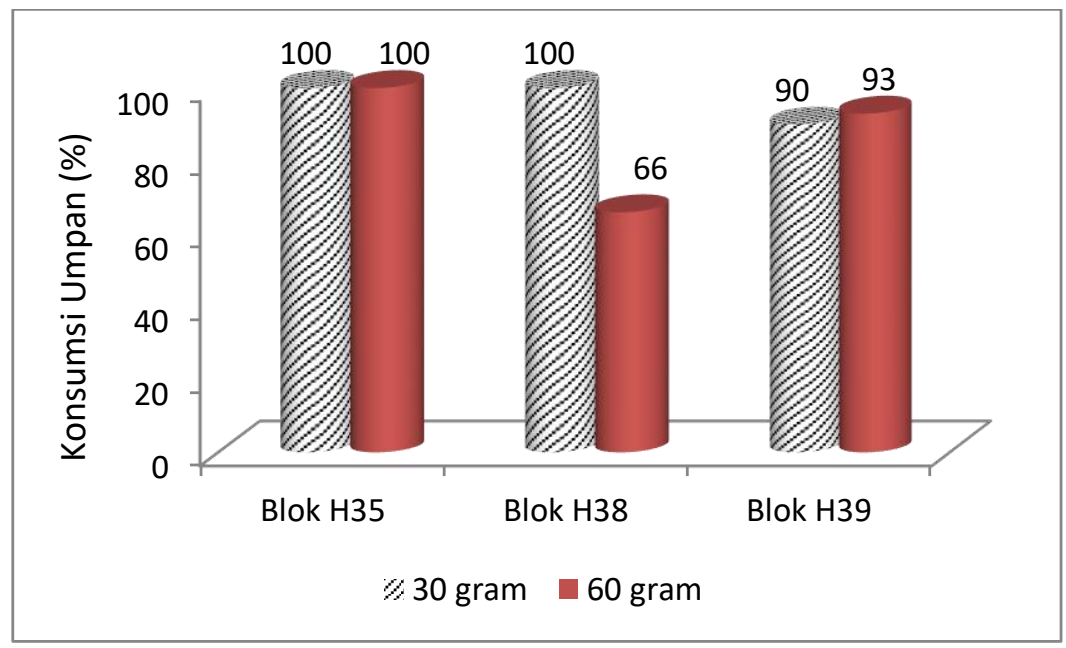

Gambar 2. Nilai rata-rata konsumsi umpan Hexaflumuron dosis 30 gram dan 60 gram yang dikonsumsi oleh rayap tanah Coptotermes curvignathus Holmgren di kebun kelapa sawit (Average value of Hexaflumuron bait consumption on dosage 30 gram and 60 gram after consumption by subterranean termites Coptotermes curvignathus Holmgren in oil palm plantation) 


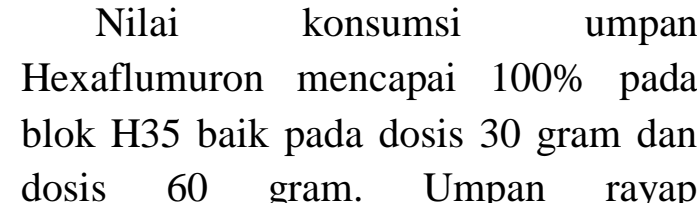
Hexaflumuron bekerja dengan lambat dan bukan racun kontak dan hal ini menyebabkan rayap yang mengkonsumsi umpan tidak langsung mengalami kematian setelah mengkonsumsi umpan. Bahan aktif Hexaflumuron menghambat proses pembentukan khitin dan proses kematian rayap terjadi ketika rayap yang telah mengkonsumsi umpan akan berganti kulit. Khitin yang baru tidak bisa terbentuk sementara rayap telah melakukan pembelahan sel khitin yang lama dan akhirnya terjadi proses dehidrasi yang menyebabkan kematian rayap. Hasil analisis keragaman menunjukkan konsumsi umpan Hexaflumuron pada dosis yang berbeda tidak berpengaruh nyata. Hal ini menunjukkan dosis umpan tidak berpengaruh terhadap jumlah yang dikonsumsi rayap. Rayap akan mengkonsumsi semua umpan yang diberikan.

Rayap mengalami eliminasi pada pekan ke empat sampai pada pekan ke tujuh. Waktu eliminasi selama tujuh pekan terjadi pada Blok H38 dan H39 sementara pada Blok H35 eliminasi rayap terjadi lebih cepat, pada pekan ke empat untuk dosis 60 gram dan pekan ke lima untuk dosis 30 gram. Hasil penelitian ini sesuai dengan penelitian Nandika (2014) yang menyatakan efektifitas aplikasi umpan Hexaflumuron sangat berhasil di lapangan. Rata-rata waktu eliminasi antara 3 pekan sampai 6 pekan. Setelah satu bulan mengkonsumsi umpan Hexaflumuron seluruh pekerja mengalami kematian sehingga mengakibatkan anggota koloni lain tidak mendapatkan makanan. Selanjutnya kematian pekerja menyebabkan anggota koloni rayap lainnya (prajurit dan reproduktif) mengalami kematian. Kasta pekerja adalah anggota koloni rayap yang bertanggung jawab dalam memberikan makanan bagi kasta prajurit dan reproduktif. Hasil pengamatan pada tanaman kelapa sawit dengan dosis 30 gram, pada pekan ke empat tidak ditemukan kasta pekerja dan hanya kasta prajurit yang terdapat di liang kembara dalam jumlah yang sedikit. Kejadian yang sama ditemukan pada tanaman kelapa sawit dengan dosis 60 gram pada pekan ke tiga.

Waktu eliminasi rayap paling cepat terjadi pada Blok H35, baik pada dosis 30 gram dan dosis 60 gram. Nilai konsumsi umpan mencapai $100 \%$ pada kedua dosis umpan. Sementara pada Blok H38 dan H39 waktu eliminasi lebih lambat yaitu selama tujuh pekan. Lambatnya waktu eliminasi di Blok H38 dan H39 disebabkan kondisi sekitar tanaman kelapa sawit yang banyak terdapat tunggak kayu dan serasah, sehingga menjadi sumber makanan yang cukup untuk dikonsumsi rayap. Kondisi lingkungan tersebut membuat umpan yang ada pada tanaman kelapa sawit lama untuk dikonsumsi oleh rayap. Waktu eliminasi rayap disajikan pada Gambar 3 dan Gambar 4. 
JURNAL TENGKAWANG (2017)

Vol. 7 (2) : 100 - 109

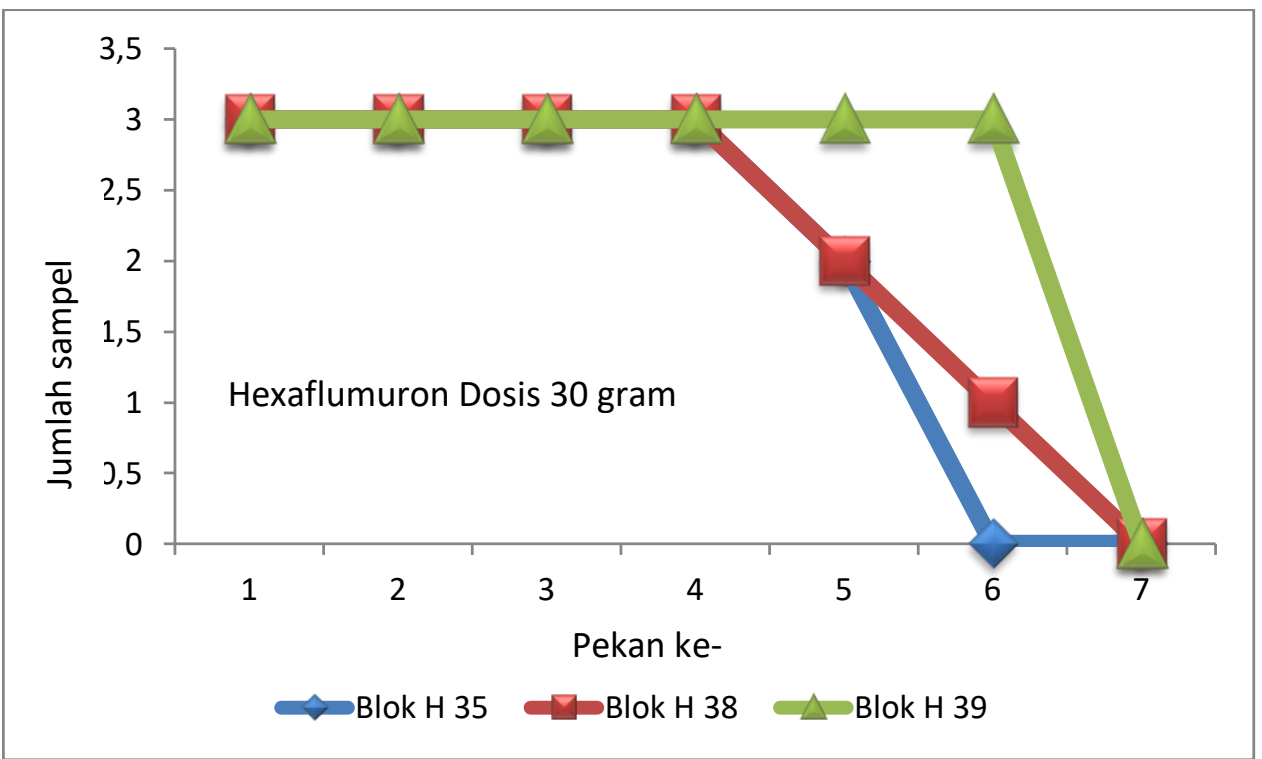

Gambar 3. Waktu eliminasi rayap Coptotermes curvignathus Holmgren di kebun kelapa sawit setelah mengkonsumsi umpan Hexaflumuron dosis 30 gram (Elimination time of subterranean termites Coptotermes curvignathus Holmgren in oil palm plantation after consumption Hexaflumuron bait on dosage 30 gram)

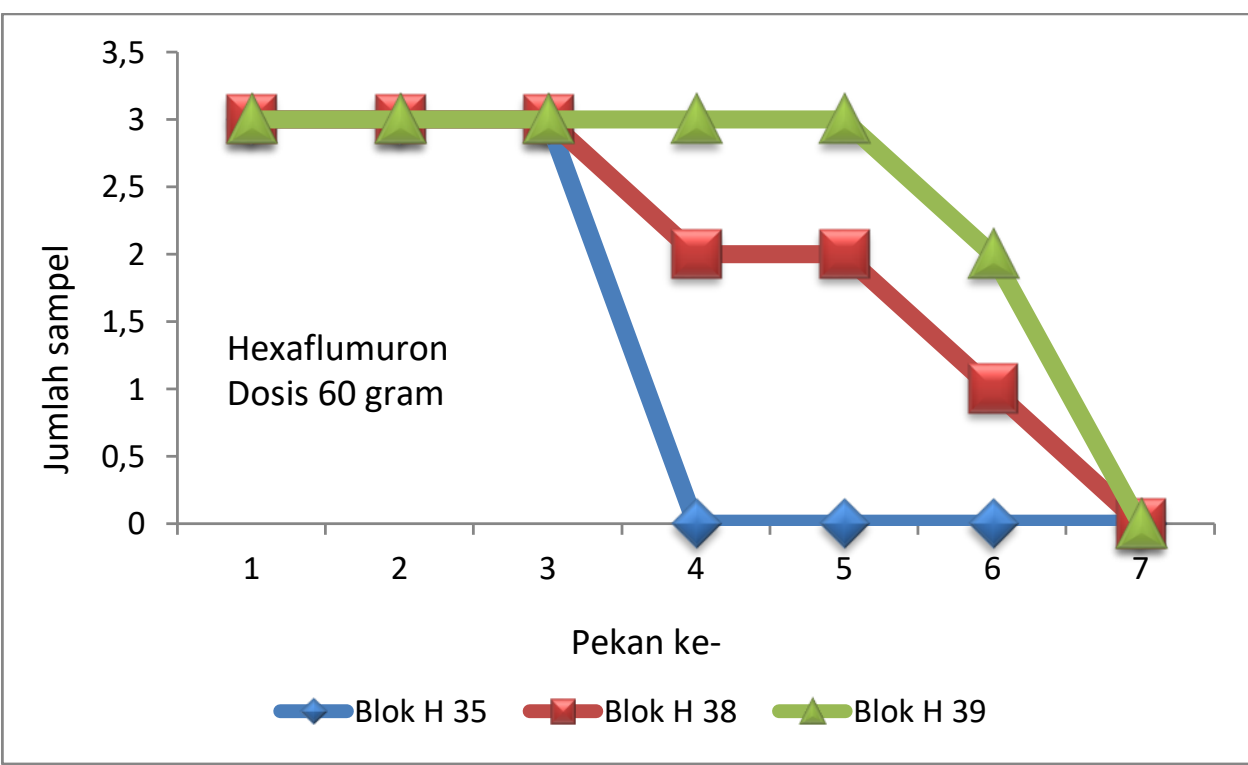

Gambar 4. Waktu eliminasi rayap Coptotermes curvignathus Holmgren di kebun kelapa sawit setelah mengkonsumsi umpan Hexaflumuron dosis 60 gram (Elimination time of subterranean termites Coptotermes curvignathus Holmgren in oil palm plantation after consumption Hexaflumuron bait on dosage 60 gram)

Serangan rayap pada perkebunan kelapa sawit menimbulkan kerugian yang sangat besar. Penelitian pengendalian rayap menggunakan bahan hayati telah 
mulai dikembangkan. Penelitian Sucipto (2009) menggunakan nematode Heterorhabditis isolat lokal Madura untuk mengendalikan rayap tanah (Macrotermes $s p$ ) di Kabupaten Bangkalan dan Sampang. Panjaitan dkk (2014) merancang alat dengan menggunakan gelombang elektromagnetik untuk mengendalikan rayap. Wardyani dkk (2017) menggunakan ekstrak limbah kulit kayu Bakau (Rhizophora apiculata Blume) untuk pengendalian rayap. Oramahi dkk (2014a) menggunakan asap cair untuk pengendalian rayap Coptotermes curvignathus Holmgren, dilanjutkan penelitian Oramahi dkk (2014b) menggunakan asap cair dari kayu Laban (Vitex pubenscens Vahl) dan pemanfaatan batang kelapa sawit untuk pembuatan asap cair dalam pengendalian serangan rayap (Oramahi dkk 2015). Waktu eliminasi rayap dengan dosis 30 gram mencapai 6 7 pekan, sedangkan waktu eliminasi rayap dengan dosis 60 gram selama $4-7$ pekan. Hasil analisis keragaman menunjukkan konsumsi umpan Hexaflumuron pada dosis yang berbeda tidak berpengaruh nyata terhadap waktu eliminasi rayap. Dosis umpan 30 gram mampu mengeliminasi rayap pada pekan ke enam sementara dosis umpan 60 gram lebih cepat yaitu hanya empat pekan. Namun untuk efisiensi dalam aplikasi maka dosis 30 gram telah cukup digunakan untuk pengendalian serangan rayap di perkebunan kelapa sawit.

\section{Kesimpulan}

1. Umpan rayap dengan bahan aktif Hexaflumuron dikonsumsi oleh rayap Coptotermes curvignathus Holmgren dan tidak memiliki efek daya tolak (repellent).

2. Umpan rayap dengan bahan aktif Hexaflumuron efektif dalam mengendalikan serangan rayap Coptotermes curvignathus Holmgren di perkebunan kelapa sawit.

3. Waktu eliminasi rayap Coptotermes curvignathus Holmgren setelah mengkonsumsi umpan rayap dengan bahan aktif Hexaflumuron mencapai 4 pekan sampai 7 pekan.

\section{Saran}

1. Pengaplikasian umpan rayap dengan bahan aktif Hexaflumuron pada tanaman kelapa sawit agar pada pagi hari serta memperhatikan keadaan lingkungan di sekitar tanaman kelapa sawit.

2. Umpan rayap dengan bahan aktif Hexaflumuron agar diletakkan pada liang kembara rayap yang aktif sehingga cepat dikonsumsi rayap dan proses eliminasi dapat berjalan dengan baik.

\section{DAFTAR PUSTAKA}

Diba F, Toni I., Irianto M.Y. 2016. Field Evaluation of Hexaflumuron Bait for Colony Elimination of the Subterranean Termite Coptotermes curvignathus Holmgren in Oil Plam Plantation in West Kalimantan Indonesia. Proceeding $11^{\text {th }}$ Pacific Rim Termites Research Group, 18-19 April 2016, Kunming, China

Diba, F. 2015. Termites incidence and characteristics of damage on oil palm plantation in West Kalimantan Indonesia. Proceeding The $5^{\text {th }}$ International Symposium 
for Sustainable Humanosphere (ISSH), Jakarta, 29-30 September 2015.

Dinas Perkebunan Provinsi Kalimantan Barat, 2016. Statistik Perkebunan Kalimantan Barat.

Habibi, Diba F, Siahaan S. 2017. Keanekaragaman Jenis Rayap di Kebun Kelapa Sawit PT. Bumi Pratama Khatulistiwa Kecamatan Sungai Ambawang Kabupaten Kubu Raya. Jurnal Hutan Lestari, 5 (2): 481-489 ISSN: 2338 3127

Hermawan, A., F. Diba, Y. Mariani, D. Setyawati, Nurhaida. 2014. Sifat Kimia Batang Kelapa Sawit (Elaeis guinensis Jacq) Berdasarkan Letak ketinggian dan Kedalaman Batang. Jurnal Hutan Lestari, 2 (3): 2338 - 3127. ISSN: $2338-3127$

Nabu, Diba F, Dirhamsyah M. 2015. Aktivitas Anti Rayap Minyak Atsiri dari Kulit Jeruk Citrus nobilis Var. microcarpa Terhadap Rayap Tanah Coptotermes curvignathus Holmgren. Jurnal Hutan Lestari, 3 (1):. ISSN: 2338 -3127 .

Nandika D. 2014. Rayap, Hama baru di Kebun Kelapa Sawit. SEAMEO BIOTROP. Bogor.

Nandika D, Rismayadi Y, dan Diba F. 2015. Rayap, Biologi dan Pengendaliannya. Edisi 2. Muhammadiyah University Press. Surakarta.

Risza, S. 1994. Upaya Peningkatan Produktivitas Kelapa Sawit Indonesia. Kanisius. Yogyakarta.

Oramahi H.A., Diba F, Wahdina, Nurhaida, Yoshimura T. 2015. Optimization of Production of
Lignocellulosic Biomass Bio-oil from Oil palm Trunk. Procedia Environmental Sciences Journal Vol 28: 769-777. ISSN 1878-0296

Oramahi, H.A., Diba F., Nurhaida. 2014a. New Bio Preservatives from Lignocelluloses Biomass Bio-oil for Anti termites Coptotermes curvignathus Holmgren. Procedia Environmental Sciences Vol 20, 778-784 ISSN 1878-0296

Oramahi H.A., Diba F., Purwati, Iskandar, Wahdina. 2014b. Efikasi Asap Cair Dari Kayu Laban (Vitex pubenscens) Terhadap Rayap Coptotermes curvignathus. Jurnal Hama Dan Penyakit Tumbuhan Tropika. 14 (1) ISSN: 1411 7525. Terakreditasi B No. 80/DIKTI/Kep/2012 Tgl 13. Desember 2012

Panjaitan S.D., Diba F, Hadary F., Yoshimura T. 2014. Electrical Performance and Effect of Frequency Electromagnetic Waves on Subterranean Termites Coptotermes curvignathus Holmgren. Journal of Electromagnetic Analysis and Applications, Vol 6: 1-7. ISSN Print 1942-0730 ISSN Online 1942-0749

Peters BC, Broadbent S, Dhang P. 2008. Evaluating a baiting system for management of termites in landscape and orchard trees in Australia, Hong Kong, Malaysia and the Philippines. Proceedings of the Sixth International Conference on Urban Pests, 379383

Pratiwa C, Diba F, Wahdina. 2015. Bioaktivitas Ekstrak Etanol Buah Mengkudu (Morinda citrofolia L.) 
Terhadap Rayap Tanah (Coptotermes curvignathus Holmgren) Jurnal Hutan Lestari, 3 (2):227-233 ISSN: $2338-3127$

Salam DM, Mukarlina, Diba F. Protobiont 2014 Pengendalian Rayap Tanah Coptotermes curvignathus Holmgren Menggunakan Ekstrak Daun Gulma Sembung Rambat (Mikania micrantha Kunth) Jurnal Protobiont, 3 (2) : 87 - 92

Sari TE, Turnip M, Diba F. 2014. Pemanfaatan Daun Sirsak (Annona muricata L.) pada Media Umpan sebagai Pengendali Rayap Tanah (Coptotermes curvignathus Holmgren) Jurnal Protobiont, 3 (1): 71 - 74

Sucipto. 2009. Efektifitas Teknik Aplikasi Nematoda Heterorhabditis Isolat Lokal Madura Sebagai Agens Hayati Pengendalan Rayap Tanah (Macrotermes sp) di Kabupaten Bangkalan dan Sampang. Jurnal Embriyo, 6 (1). Unijoyo.

Tampubolon, Diba F, Nurhaida. 2016. Studi Umpan Rayap Copton 0.5 RB Dalam Pengendalian Rayap Coptotermes curvignathus Holmgren Pada Perkebunan Kelapa Sawit Elaeis guineensis Jacq Jurnal Hutan Lestari, 4 (3):335-343 ISSN: $2338-3127$

Toni I. Diba F, Nurhaida. 2015. Pengendalian rayap Coptotermes curvignathus Holmgren dengan umpan rayap Hexaflumuron bentuk briquette pada perkebunan kelapa sawit (Elaeis guineensis Jacq) Jurnal Hutan Lestari, 4 (1):9-20 ISSN: 2338 - 3127

Wardyani Y. Diba F. Nurhaida. 2017. Pewarnaan Kayu Sengon
(Paraserianthes falcataria Linn) dari Ekstrak Limbah Kulit Kayu Bakau (Rhizophora apiculata Blume) : Uji Ketahanan warna dan keawetan kayu. Jurnal Hutan Lestari, 5 (3):618-628. 